
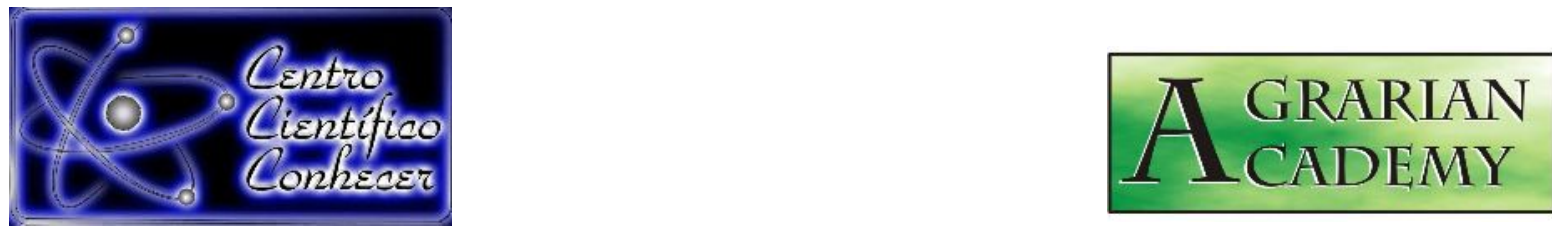

\title{
PRODUTIVIDADE E CUSTO OPERACIONAL EFETIVO DE UMA PROPRIEDADE RURAL DA REDE DE FAZENDAS ALFA DO AGRIHUB
}

Odair Henrique de Paulo Dias ${ }^{1}$, Poliana Torres Silva ${ }^{2}$, Aline Regina Piedade ${ }^{3}$, Patrícia Barbosa Souza ${ }^{4}$, Gláucia Miranda Ramirez ${ }^{5}$

1 - Graduando em Agronomia pela UFMT, Campus Cuiabá-MT, Técnico em Agropecuária pelo IFMT, Campus Juína-MT.

2 - Graduanda em Agronomia pela UFMT, Campus Cuiabá-MT.

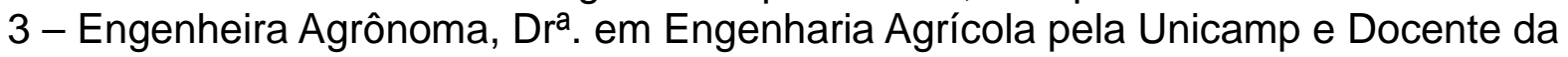

Faculdade de Agronomia e Zootecnia (FAAZ/UFMT).

4 - Gestora do Agronegócio pela UFV, Líder de Parcerias do Instituto AgriHub/FAMATO.

5 - Engenheira Agrônoma, Dra ${ }^{\text {a }}$ em Engenharia Agrícola pela Unicamp e Docente da Faculdade de Agronomia e Zootecnia (FAAZ/UFMT).

Contato: henriqueodair9@gmail.com

Recebido em: 15/12/2021 - Aprovado em: 15/12/2021 - Publicado em: 30/12/2021

DOI: 10.18677/Agrarian_Academy_2021B6

trabalho licenciado sob licença Creative Commons Attribution-NonCommercial-NoDerivatives 4.0 International License.

\section{RESUMO}

Devido a relevância da discussão da produtividade na agricultura, torna-se necessário a otimização racional quanto ao uso dos recursos. Diante dessa afirmação buscou-se, como objetivo, analisar a evolução da produtividade da soja e dos Custos Operacionais Efetivos (COE) de uma propriedade rural em Poconé-MT, nas safras entre 2017/2018 e 2020/2021. O método de abordagem utilizado no processo de investigação foi de caráter comparativo, com abordagem do problema de forma quantitativa. $O$ tipo de pesquisa foi exploratório e as fontes de informação foram extraídas dos registros dos dados do software de gestão financeira utilizado pela propriedade rural e de meio bibliográfico. Tratou-se de um estudo de caso, de abordagem descritiva, sendo representada por meio de gráficos e tabelas. Concluiuse que: (i) as safras 2017/2018 e 2020/2021 foram as que apresentaram os melhores resultados; (ii) a decisão por parte do produtor em aumento de $15,63 \%$ de área na safra 2020/2021 correspondeu a um aumento de produção de 31,43\%; (iii) a propriedade estudada apresentou valores superiores de produtividade quando comparados as demais propriedades da região centro-sul de Mato Grosso; (iv) com o passar do tempo a produtividade entre os talhões ficou mais homogênea, possivelmente pelo uso de técnicas da agricultura de precisão; (v) o COE da propriedade apresentou valores superiores aos dos modais das demais propriedades da região centro-sul de Mato Grosso; (vi) aproximadamente $80 \%$ do COE correspondeu ao custeio em todas as safras analisadas validando a aplicação do Diagrama de Pareto como ferramenta de gestão da qualidade na produção.

PALAVRAS-CHAVE: Agronegócio; Gestão estratégica de Custo, Glycine max L. 


\title{
PRODUCTIVITY AND EFFECTIVE OPERATING COST OF A RURAL PROPERTY THE OF "NETWORK OF FARMS ALFA" THE AGRIHUB
}

\begin{abstract}
Due to the relevance of the discussion of productivity in agriculture, it is necessary to rationally optimize the use of resources. In light of this statement, the objective was to analyze the evolution of soy productivity and the Effective Operating Costs (EOC) of a rural property in Poconé-MT, in the harvests between 2017/2018 and 2020/2021. The method of approach used in the comparative investigation process, with a quantitative approach. The type of research was exploratory and the sources of information were extracted from the data records of the financial management software, used by the rural property and from bibliographical means. It was a case study, with a descriptive approach, represented by graphs and tables. It was concluded that: (i) the 2017/2018 and 2020/2021 harvests were the ones that presented the best results; (ii) the decision by the producer to increase the area by $15.63 \%$ in the $2020 / 2021$ harvest corresponded to an increase in production of $31.43 \%$; (iii) the studied property presented higher productivity values when compared to other properties in the center-south region of Mato Grosso; (iv) over time the productivity between the stands became more homogeneous, possibly due to the use of precision farming techniques; (v) the EOC the property presented values higher than the modals of other properties in the center-south region of Mato Grosso; (vi) approximately $80 \%$ of the EOC corresponded to the defrayal in all analyzed crops, validating the application of the Pareto Diagram as a quality management tool in production.
\end{abstract}

KEYWORDS: Strategic cost management, Glycine max L., Agribusiness

\section{INTRODUÇÃO}

A soja (Glycine max L.) é uma planta herbácea da família Leguminosae que atualmente possui grande importância econômica tanto para o Brasil como para o Estado de Mato Grosso. A cultura ocupa cerca de $50 \%$ de toda a área de produção de grãos no mundo e a demanda pelo grão continua crescendo, o que tem motivado os produtores a investir em tecnologias para aumentar produtividade por área (RICHETTI, 2018).

O nível tecnológico alcançado pelos produtores de soja brasileiros atingiu patamares expressivos nos últimos anos, gerando um aumento na produtividade da cultura. Apesar desse aumento, estudos realizados pela Conab (2017), mostraram que quando se compara o aumento da produtividade nos últimos 10 anos não há evidências de crescimento significativo, mostrando que existe uma barreira a ser ultrapassada. O mesmo relatório afirma que por meio de inovação, seja tecnológica, de insumos ou no processo produtivo é possível romper o atual equilíbrio de produção estabelecido.

A soja é uma das principais commodities produzidas e exportadas pelo Brasil, gerando um expressivo retorno econômico, já o Estado de Mato Grosso é o maior produtor brasileiro do grão (CONAB, 2021). Apesar de estar localizado no cerrado, um bioma que tem como característica a baixa fertilidade natural e uma alta toxidez por alumínio em seu solo, apresenta qualidades favoráveis, como condições climáticas e relevo propícios para o cultivo da soja (LACERDA et al., 2015).

Apesar de toda esta eficácia, a produção de soja ainda enfrenta inúmeras dificuldades, principalmente no que diz respeito à infraestrutura e outros fatores fundamentais à produção e à logística relacionada aos grãos. Produtores 
frequentemente queixam-se das condições enfrentadas para manter suas atividades em nível competitivo em um mercado global, sujeito a inúmeros contratempos e dificuldades (PAIS;TORRES, 2018).

A fim de resolver a problemática relacionada a sustentabilidade econômica financeira de uma propriedade rural, justificam-se estudos nessa linha de pesquisa, em especial em relação à Gestão Estratégica de Custos. Portanto, o objetivo do presente trabalho foi analisar a evolução da produtividade e dos Custos Operacionais Efetivos (COE) da produção de soja na Fazenda Lagoa Dourada, situada no município de Poconé na mesorregião do centro-sul mato-grossense, nas safras compreendidas entre 2017/2018 e 2020/2021.

\section{MATERIAL E MÉTODOS}

A propriedade Lagoa Dourada, objeto do estudo, está localizada no município de Poconé - MT, situado na região centro-sul do Estado de Mato Grosso (Figura 1). As três primeiras safras de soja analisadas apresentaram áreas de produção similares, com aproximadamente 1.500 ha e na safra 2020/2021, por decisão do proprietário, ocorreu um aumento da área produtiva para 1.734,57 ha, com arrendamentos de áreas vizinhas.

A propriedade rural possui como característica: altitude de 153 metros com coordenadas geográfica de latitude $-16,09$ e longitude $-56,75$. O clima da região estudada, segundo o sistema de classificação de Koppen, é denominado Tropical Quente e Subúmido (Aw). A pluviosidade média anual da região é de $1361 \mathrm{~mm}$, cuja frequência de pluviosidade se concentra mais no verão que no inverno. A temperatura média anual, em Poconé-MT, é $26.6^{\circ} \mathrm{C}$. O tipo de solo predominante na região é o latossolo, com relevo majoritariamente plano à suave ondulado.

FIGURA 1. Localização da área do estudo. Fazenda Lagoa Dourada, município de Poconé - MT, situado na região centro-sul do Estado de Mato Grosso. (Poconé - MT, setembro/2021).

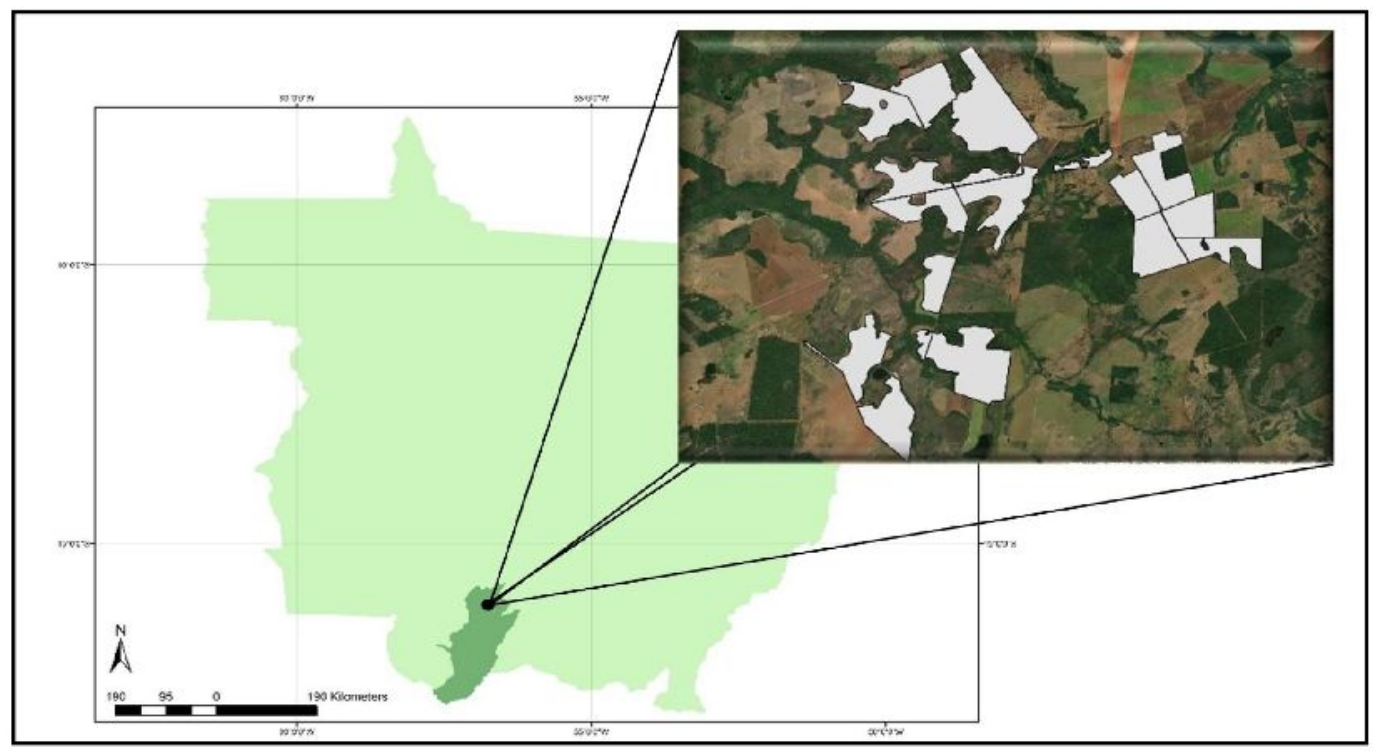

Fonte: Elaborado pelos autores (2021)

O método de abordagem utilizado nesse processo de investigação foi seguindo um procedimento metodológico de caráter comparativo, o qual realiza comparações com a intenção de verificar semelhanças e explicar as divergências. 
Quanto à natureza do estudo pode-se classificar que se tratou de uma pesquisa básica, com abordagem do problema de forma quantitativa. Quanto ao objetivo geral, o tipo de pesquisa foi de modo exploratório e as fontes de informação foram extraídas de dados de campo e por meio bibliográfico, uma vez que esse último se trata da coleta de informações em materiais impressos ou publicados na mídia. Quanto aos procedimentos técnicos, tratou-se de um estudo de caso, com uma abordagem descritiva, sendo representado por meio de gráficos e tabelas.

Conforme Gil (2009), o estudo de caso consiste na análise profunda e exaustiva de um único objeto de maneira que se possa conhecê-lo de forma ampla e detalhada. A propriedade rural Lagoa Dourada foi escolhida devido ao fato de pertencer a Rede de Fazendas Alfa (RFA), do Instituto AgriHub, da Federação da Agricultura e Pecuária do Estado de Mato Grosso (FAMATO). FAMATO trata-se de um instituto privado, que representa os sindicatos rurais de Mato Grosso, consequentemente representa o produtor rural.

O AgriHub surgiu em 2016 como uma iniciativa do Instituto Mato-grossense de Economia Agropecuária (IMEA) diante da necessidade de estreitar o contato do produtor rural com as novas tecnologias que surgiam no mercado. Desde então, inúmeras ações foram realizadas em todo o estado de Mato Grosso, promovendo o diagnóstico das dores do setor produtivo e fomentando a interação dos produtores com empresas de base tecnológica com soluções para o agronegócio (agtechs). Em 2020, com o apoio do sistema FAMATO, o AgriHub se institucionalizou como o primeiro Hub de inovação do agronegócio do estado, com o objetivo de promover difusão tecnológica por meio de ações voltadas para a inovação aberta, capacitação digital dos profissionais do setor e desenvolvimento de metodologias de apoio a decisão do produtor (AGRIHUB,2020).

A fim de trazer o produtor para próximo do desenvolvimento do processo de difusão tecnológica de maneira participativa, criou-se o conceito da Rede de Fazendas Alfa (RFA), um grupo constituído por produtores rurais que participam do desenvolvimento de metodologias e realização de testes de soluções inovadoras. A RFA foi idealizada e criada com o objetivo de gerar uma conexão com produtores early adopters e assim poder entender os problemas e necessidades do campo; de apoiar na escolha de novas soluções tecnológicas; de acompanhar testes reais de soluções inovadoras e de apoiar no processo geral de difusão tecnológica através da sua rede de influência (IMEA, 2018).

Com base nisso, define-se o "perfil de um produtor alfa" (AGRIHUB, 2021). Os atributos desejados ao "produtor alfa" são: ser visionário, aberto ao novo, com apetite ao risco e valorizar a pesquisa científica. Além das características acima, que geralmente estão presentes na maioria dos produtores rurais, a principal característica desejada do perfil alfa é a disposição em ser um ator ativo dentro da RFA, contribuindo com o desenvolvimento dos testes tecnológicos e a difusão dos resultados entre os demais produtores (IMEA,2018). Isso embasa a escolha da propriedade rural (Fazenda Lagoa Dourada, em Poconé-MT), objeto desta pesquisa.

Importante salientar que, neste caso em específico, obtiveram-se dados de uma única propriedade rural, cujos resultados trazem a realidade da propriedade agrícola em questão, portanto não podendo ser generalizados. A propriedade rural do estudo utiliza um software de gestão financeira, que centraliza informações referentes a produção da soja. Tal software tem por objetivo aprimorar o controle dos processos produtivos e assim, tornar a vida do profissional rural mais eficiente e assertiva quanto às tomadas de decisões. 
Dessa forma, visando atingir ao objetivo proposto da pesquisa, utilizaram-se os dados das quatro últimas safras de soja que estavam registrados no software de gestão, utilizados pela propriedade rural. A safras analisadas foram: (1) Safra 2017/2018; (2) Safra 2018/2019; (3) Safra 2019/2020 e; (4) Safra 2020/2021.

Após a estruturação dos dados em planilhas eletrônicas, com o auxílio do Software Microsoft Excel, deu-se início a análise da evolução da produtividade bem como a análise do Custo Operacional Efetivo (COE). Para a análise da evolução da produtividade, levantou-se os dados de cada talhão com sua respectiva safra (extraídos do software de gestão financeira, em sacas de $60 \mathrm{~kg}$ por hectare), comparando-os entre si, com a média ponderada de produtividade de cada safra colhida e que, por fim, comparava-se com os dados modais de produtividade da região estudada, publicados pelo Instituto Mato-grossense de Economia Agropecuária (IMEA).

As referências dos dados fornecidos pelo IMEA foram relacionadas à produção da soja transgênica da região centro-sul do Estado de Mato Grosso. O Custo Operacional Efetivo (COE) da propriedade foi gerado a partir da metodologia para Custos de Produção utilizada pelo IMEA (2020). Segundo a metodologia descrita pelo IMEA, o COE envolve todos os desembolsos do produtor rural no ano e é entendido como o custo a curto prazo.

O COE consolida basicamente os custos de: A - Custeio, que envolve, custos com sementes, fertilizantes e corretivos, defensivos, outros insumos, operações mecanizadas, serviços terceirizados e mão-de-obra; B - Manutenção; C - Impostos e taxas; D - Financeiras; E - Pós-produção; F- Outros custos e G - Arrendamento (conforme Quadro 1).

QUADRO 1. Composição do Custo Operacional

\begin{tabular}{|l|}
\hline \multicolumn{1}{|c|}{ COE (Custo Operacional Efetivo) } \\
\hline \\
1. Sementes \\
2. Fertilizantes e Corretivos \\
3. Defensivos \\
4. Outros insumos \\
5. Operações mecanizadas \\
6. Serviços terceirizados \\
7. Mão-de-Obra \\
B. Manutenção \\
C. Impostos e taxas \\
D. Financeiras; \\
E. Pós-produção \\
F. Outros custos \\
G. Arrendamento
\end{tabular}

Efetivo (COE), seguindo metodologia IMEA, 2020.

Fonte: elaborado pelos autores (2021)

Com dados exportados e tratados do software de gestão financeira utilizado pela propriedade, deu-se início ao cálculo do COE para cada safra estudada. Posteriormente, o COE/safra da propriedade foi comparado com os dados disponibilizados pelo IMEA para a região produtora (centro-sul do estado). 
Por fim, observou-se como limitação metodológica do estudo de caso em questão, a análise somente da evolução da produtividade e do COE, sem haver a integração com Custo Operacional Total (COT) e o Custo Total (CT) do sistema produtivo. Salienta-se ainda que o estudo foi composto por uma única propriedade rural, haja vista a escassez de registro, detalhamento e disponibilização dos dados por parte de outros produtores rurais.

\section{RESULTADOS E DISCUSSÃO}

Visando analisar os dados da produção de soja, das quatro últimas safras, sendo: (1) Safra 2017/2018; (2) Safra 2018/2019; (3) Safra 2019/2020 e; (4) Safra 2020/2021, que estavam registrados no software de gestão financeira utilizados pela propriedade rural, abordar-se-á neste item os resultados e discussões quanto a evolução da produtividade e do Custo Operacional Efetivo (COE). Para melhor entendimento, decidiu-se subdividir em dois subitens a saber: (i) Caracterização da área produtiva e resultados relacionados a produtividade e (ii) Resultados relacionados ao Custo Operacional Efetivo (COE).

\section{Caracterização da área produtiva e resultados relacionados a produtividade}

Devido a necessidade de caracterização da área produtiva da propriedade rural estudada, verifica-se na Tabela 1 informações relacionadas a área total colhida, em hectares; a produção total, em toneladas e em sacas de $60 \mathrm{~kg}$ e as produtividades médias, em sacas de $60 \mathrm{~kg}$ por hectare, obtidas para as quatro safras analisadas.

TABELA 1. Caracterização da produção da soja da Fazenda Lagoa Dourada, sendo área total colhida (ha), produção total (t) e (sacas de $60 \mathrm{~kg}$ ) e produtividade média ponderada (sacas/ha) obtida para as quatro safras analisadas.

\begin{tabular}{ccccc}
\hline Safras & $\begin{array}{c}\text { Área colhida } \\
\text { (ha) }\end{array}$ & Produção (t) & $\begin{array}{c}\text { Produção } \\
\text { (saca 60kg) }\end{array}$ & $\begin{array}{c}\text { Produtividade } \\
\text { Média } \\
\text { (saca/ha) }\end{array}$ \\
\hline $\mathbf{2 0 1 7 / 2 0 1 8}$ & $1.503,00$ & $5.784,35$ & $96.405,82$ & 64,14 \\
$\mathbf{2 0 1 8 / 2 0 1 9}$ & $1.501,84$ & $5.282,27$ & $88.037,86$ & 58,62 \\
$\mathbf{2 0 1 9 / 2 0 2 0}$ & $1.473,36$ & $4.373,99$ & $72.899,86$ & 49,48 \\
$\mathbf{2 0 2 0 / 2 0 2 1}$ & $1.734,57$ & $6.771,23$ & $112.853,81$ & 65,06 \\
\hline
\end{tabular}

Fonte: elaborado pelos autores (2021)

Nota-se que as três primeiras safras analisadas apresentam áreas de produção similares, com aproximadamente 1.500 ha e que na safra 2020/2021 ocorreu um aumento para 1.734,57 ha, acrescendo em 15,63\% a área de cultivo em relação às safras anteriores, com aumento de 237,65 ha (Tabela 1). Tal decisão, por parte do produtor, em aumentar $15,63 \%$ da área produtiva na safra 2020/2021, correspondeu a um aumento de produção de $31,43 \%$. As safras $2017 / 2018$ e 2020/2021 foram as que apresentaram os melhores resultados para produtividade, com 64,14 e 65,06 kg/ha, respectivamente.

Importante explanar que o modo de divisão e nomenclatura dos talhões registrados, para as safras 2017/2018, 2018/2019 e 2019/2020, no software de gestão são semelhantes e na safra 2020/2021 foram acrescentados três talhões denominados TB 01, TB 02 e TB 03 (Tabela 2). 
TABELA 2. Descrição da nomenclatura dos talhões e respectivas áreas (em ha) para produção da soja da Fazenda Lagoa Dourada, em Poconé-MT, nas quatro safras analisadas.

\begin{tabular}{ccccc}
\hline \multirow{2}{*}{ Talhão } & \multicolumn{4}{c}{ Áreas/talhão (ha) } \\
\cline { 2 - 5 } & $\mathbf{2 0 1 7 / 2 0 1 8}$ & $\mathbf{2 0 1 8 / 2 0 1 9}$ & $\mathbf{2 0 1 9 / 2 0 2 0}$ & $\mathbf{2 0 2 0 / 2 0 2 1}$ \\
\hline TC 01 & 225,51 & 225,51 & 225,51 & 225,51 \\
TC 02 & 98,33 & 98,33 & 98,33 & 98,33 \\
TL 01 & 112,94 & 112,94 & 112,94 & 112,94 \\
TL 02 & 87,64 & 87,64 & 87,64 & 87,64 \\
TL 03 & 84,01 & 84,01 & 84,01 & 84,01 \\
TL 04 & 60,33 & 60,33 & 60,33 & 60,33 \\
TR 01 & 64,67 & 64,67 & 64,67 & 64,67 \\
TR 02 & 109,91 & 109,91 & 109,91 & 109,91 \\
TR 03 & 104,06 & 104,06 & 104,06 & 104,06 \\
TR 04 & 82,35 & 82,35 & 82,35 & 82,35 \\
TR 05 & 72,71 & 72,71 & 72,71 & 72,71 \\
TR 06 & 16,74 & 16,74 & 16,74 & 16,74 \\
TR 07 & 33,98 & 33,98 & 33,98 & 33,98 \\
TR 08 & 118,93 & 118,93 & 118,93 & 118,93 \\
TR 09 & 193,13 & 193,13 & 193,13 & 193,13 \\
TB 01 & - & - & - & 112,59 \\
TB 02 & - & - & - & 111,86 \\
TB 03 & - & - & - & 13,20 \\
\hline
\end{tabular}

Fonte: elaborado pelos autores (2021)

Observando a Figura 2, nota-se a disposição dos talhões, em cinza, nas safras 2017/2018, 2018/2019, 2019/2020 e, em amarelo, os talhões denominados TB 01, TB 02 e TB 03, que foram acrescentados na safra 2020/2021, correspondendo a um aumento de $15,63 \%$ da área produtiva. Parte-se da hipótese de aumento da área de cultivo da referida safra ocorreu por novos contratos de arrendamento efetivados pelo produtor rural.

FIGURA 2. Imagens da Fazenda Lagoa Dourada, em Poconé/MT, com destaque na área de cultivo da soja para as safras. 2017/2018, 2018/2019, 2019/2020 (em cinza) e aumento da área produtiva, na safra 2020/2021 (em amarelo).

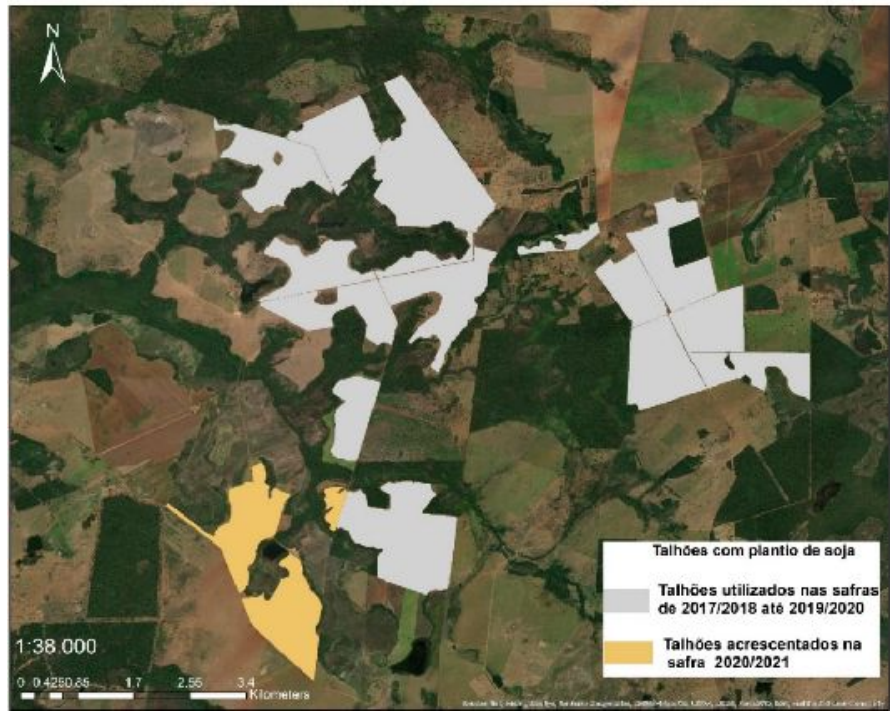

Fonte: elaborado pelos autores (2021) 
Na Figura 3 observa-se a produtividade por talhão, em sacas de $60 \mathrm{~kg} / \mathrm{ha}$, nas safras estudadas na qual é possível observar certa homogeneidade de produtividade dos talhões, em especial para a safra 2020/2021. Nesta figura, optou-se por excluir os dados referente aos talhões TB 01 e TB 02 da safra 2020/2021 para título de ilustração, de modo a demonstrar a concentração e homogeneidade ao longo das safras. Entretanto, os dados de produtividade das áreas TB 01, TB 02 e TB 03 da safra 2020/2021 foram respectivamente 57,$11 ; 51,60$ e 40,47 sacas de $60 \mathrm{~kg} / \mathrm{ha}$. Em relação a evolução da produtividade, foi possível notar que com o passar do tempo a produtividade entre os talhões ficou mais homogênea, possivelmente pelo uso de técnicas da agricultura de precisão.

FIGURA 3. Evolução da produtividade da soja por talhão, em sacas de 60kg/ha, nas safras 2017/2018, 2018/2019, 2019/2020 e 2020/2021 da Fazenda Lagoa Dourada, em Poconé/MT.

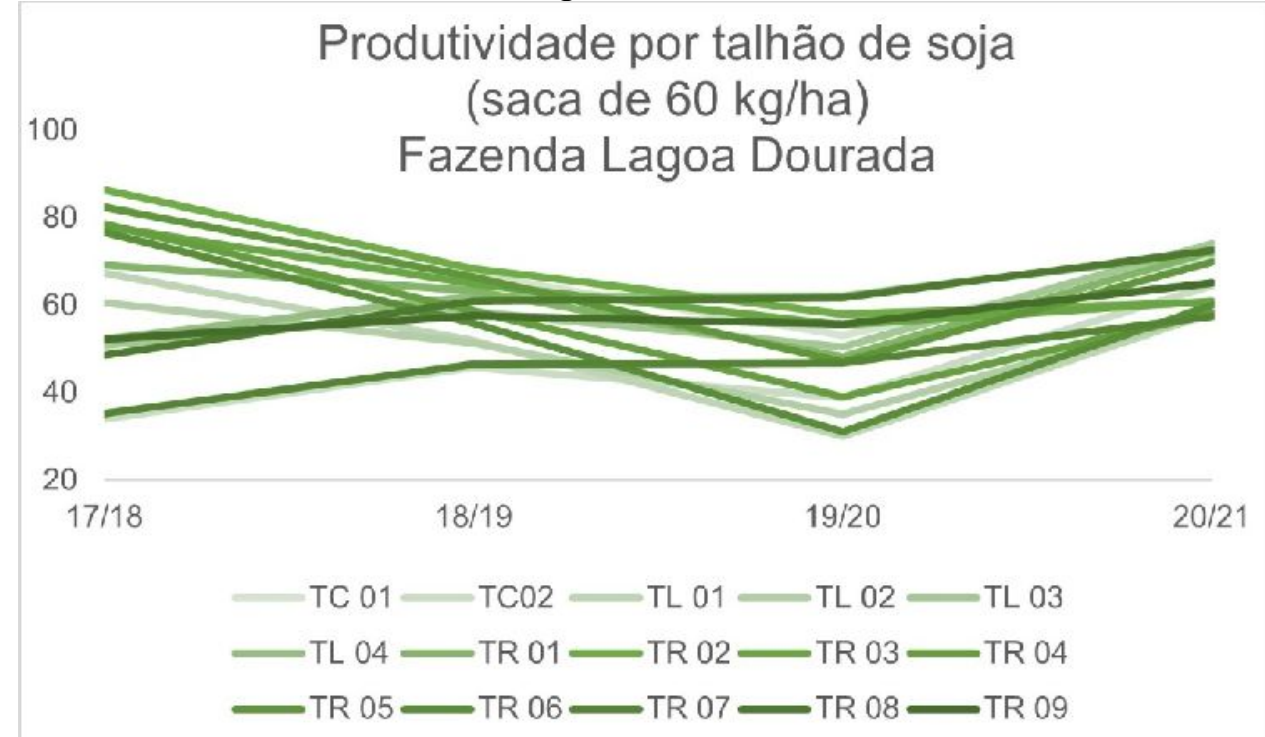

Fonte: elaborado pelos autores (2021)

Na Figura 4 tem-se a produtividade da soja, em sacas de $60 \mathrm{~kg} / \mathrm{ha}$, separadas por safras bem como a média de cada safra, sendo 2017/2018 (figura 4a), 2018/2019 (figura 4b), 2019/2020 (figura 4c) e 2020/2021 (figura 4d) da Fazenda Lagoa Dourada, em Poconé/MT. Na Figura 4 é possível observar que na safra 2017/2018, a maior produtividade ocorreu no talhão TR 02 com 86,45 sacas de 60 $\mathrm{kg} / \mathrm{ha}$ e a menor produtividade, com 33,93 sacas de $60 \mathrm{~kg} / \mathrm{ha}$, foi do talhão TC 02 . A média da safra $2017 / 2018$ foi de 64,14 sacas/ha.

Na safra 2018/2019, os mesmos talhões descritos anteriormente (TR 02 e TC 02) foram os que apresentaram maior e menor produtividade, respectivamente. $O$ talhão TR 02 teve uma produtividade de 68,42 sacas de $60 \mathrm{~kg} / \mathrm{ha}$ e o TC 02 obteve 45,75 sacas de $60 \mathrm{~kg} / \mathrm{ha}$. A média de produtividade dessa safra foi 58,62 sacas de $60 \mathrm{~kg} / \mathrm{ha}$. Ainda na mesma Figura 4, a safra 2019/2020 teve uma produtividade média de 49,48 sacas de $60 \mathrm{~kg} / \mathrm{ha}$, tendo a máxima produtividade obtida ocorrida no talhão TL 04 com 62,12 sacas de $60 \mathrm{~kg} / \mathrm{ha}$ e a mínima produtividade no talhão TL 01 com 30,00 sacas de $60 \mathrm{~kg} / \mathrm{ha}$.

A safra 2020/2021 apresentou os seguintes valores médios, máximo (talhão TL 03) e mínimo (talhão TB 03) de produtividade respectivamente com 65,06; 74,14 e 40,47 sacas de $60 \mathrm{~kg} / \mathrm{ha}$. Por meio desses resultados, pode-se observar que a 
safra 2017/2018 foi a que apresentou os melhores desempenhos em relação a produtividade. Nota-se que a produtividade obtida dos talhões ao longo do tempo fica cada vez mais próxima das médias, reforçando a prática de técnicas em agricultura de precisão.

FIGURA 4. Produtividade da soja por safra, sendo 2017/2018 (figura 4a), 2018/2019 (figura 4b), 2019/2020 (figura 4c) e 2020/2021 (figura 4d) da Fazenda Lagoa Dourada, em Poconé/MT.

Produtividade da soja Safra 2017/2018 (saca de $60 \mathrm{~kg} / \mathrm{ha}$

Fazenda Lagoa Dourada, Poconé - MT

Produtividade da soja Safra 2018/2019

Fazenda Lagoa Dourada, Poconé - MT

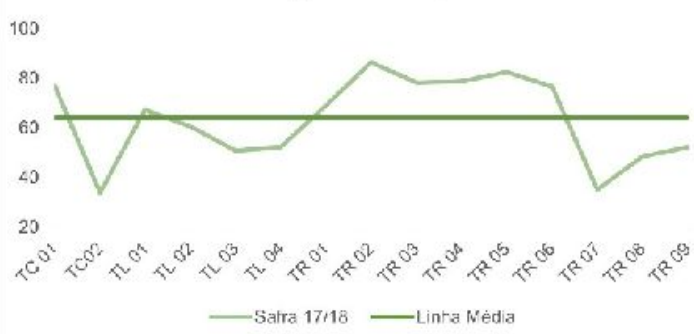

(a)

Produtividade da soja Safra 2019/2020 (saca de 60 kgiha)

Fazenda Lagoa Dourada, Poconé - MT

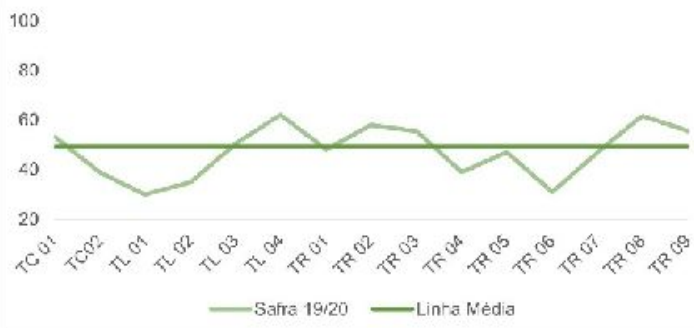

(c)

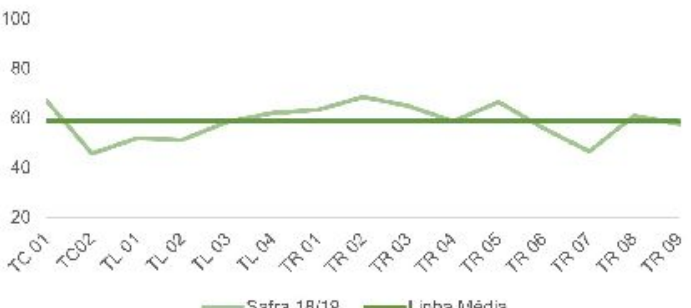

(b)

Produtividade da soja Safra 2020/2021 (saca de $60 \mathrm{~kg} / \mathrm{ha}$ )

Fazenda Lagoa Dourada, Poconé - MT

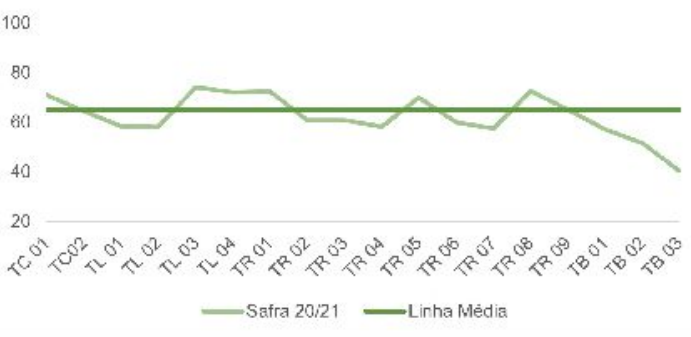

(d)

Fonte: elaborado pelos autores (2021)

Para finalizar as análises relacionadas à produtividade da propriedade rural estudada, comparação de dados em relação a região se torna importante como a descrita na Tabela 3, sendo demonstrada graficamente na Figura 5.

TABELA 3. Comparação da produtividade da soja da Fazenda Lagoa Dourada versus produtividade modal da Região Centro-Sul de MT, em sacas de $60 \mathrm{~kg}$, para as quatro safras analisadas.

\begin{tabular}{ccc}
\multirow{2}{*}{ Safra } & \multicolumn{2}{c}{ Produtividade (Saca 60 ka/ha) } \\
\cline { 2 - 3 } & $\begin{array}{c}\text { Fazenda Lagoa } \\
\text { Dourada }\end{array}$ & Modal da Região Centro-Sul de \\
$2017 / 2018$ & 64,14 & MT \\
\cline { 2 - 3 } $2018 / 2019$ & 58,62 & 52,00 \\
$2019 / 2020$ & 49,48 & 58,36 \\
$2020 / 2021$ & 65,06 & 58,88 \\
& & 62,50
\end{tabular}

Fonte: elaborado pelos autores (2021)

Os resultados das produtividades médias das safras analisadas da propriedade rural estudada são superiores aos mesmos dados quando comparados aos da mesorregião centro-sul mato-grossense, exceto para a safra 2019/2020, oportunizando outros estudos futuros a fim de aprofundar conclusões. AGRARIAN ACADEMY, Centro Científico Conhecer - Jandaia-GO, v.8, n.16 P. 64 
Pavão e Voese (2020) estudando dados de produtividade da safra 2017/2018, extraído da Companhia Nacional de Abastecimento (CONAB), encontraram dados médios inferiores aos deste estudo de caso. $O$ valor médio de produtividade que os autores calcularam foi de $3.093,00 \mathrm{Kg} / \mathrm{ha}$ na soja transgênica. Neste trabalho o valor médio de produtividade foi de $3.848,4 \mathrm{Kg} / \mathrm{ha}$.

FIGURA 5. Comparação da produtividade da soja por safra, em sacas de $60 \mathrm{~kg} / \mathrm{ha}$, da Fazenda Lagoa Dourada, em Poconé/MT e da região Centro - Sul do estado.

\section{Comparação de Produtividade \\ (saca de $60 \mathrm{~kg} / \mathrm{ha}$ ) \\ Fazenda Lagoa Dourada x Região Centro - Sul de MT}

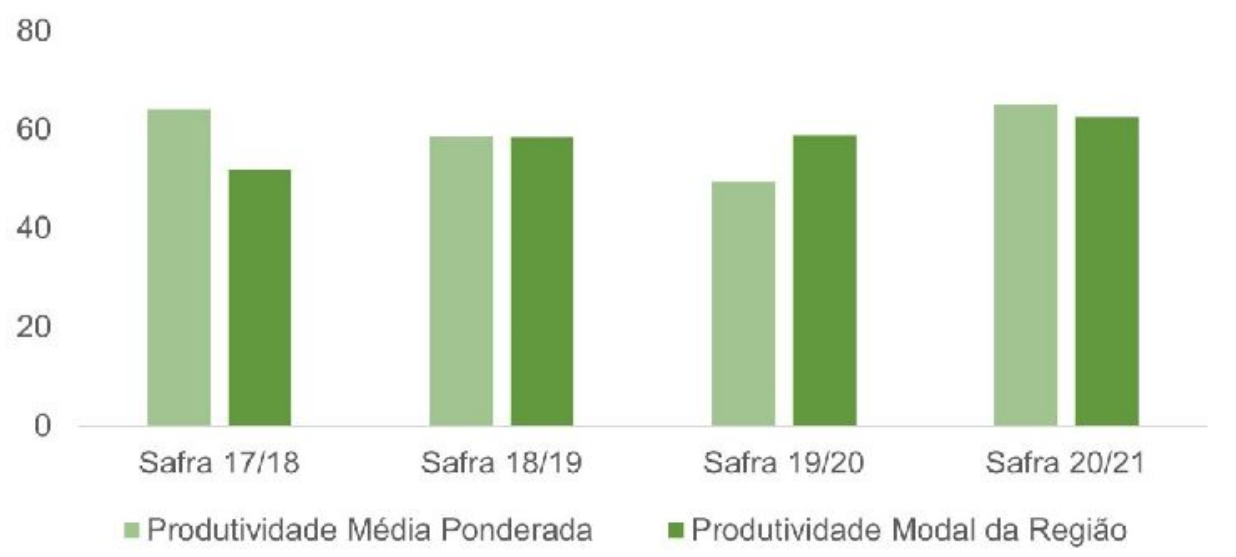

Fonte: elaborado pelos autores com base em dados do IMEA (2021)

Resultados relacionados ao Custo Operacional Efetivo (COE)

Conforme descrito no item material e métodos, o COE envolve todos os desembolsos do produtor rural no ano agrícola. Por isso entende-se o COE como o custo a curto prazo. Na Figura 6 tem-se o custeio da Fazenda Lagoa Dourada nas safras 2017/2018 e 2019/2020, com a descrição dos itens que compõe essa rubrica. Nota-se que os custos relacionados aos defensivos, fertilizantes e corretivos são os que apresentam maiores valores em ambas as safras. Pode-se notar também que o item "outros insumos" não foi utilizado nas safras analisadas. Nessa categoria deve ser computado com itens que não se encaixam como sementes, fertilizantes, corretivos e defensivos, podendo ser exemplificados custos como lona, armadilha e outros produtos/materiais utilizados na lavoura durante o ciclo da cultura.

Justifica-se a ausência dos dados de COE nas safras 2018/2019 e 2020/2021 devido à falta deles no software utilizado pela propriedade rural estudada.

Os custos que representam, conforme Figura 6, os maiores valores para o custeio foram: sementes, fertilizantes/corretivos e defensivos. O custo com sementes da Safra $2017 / 2018$ foi de $R \$ 341,09 /$ ha e na safra $2019 / 2020$ foi de $R \$ 263,40 /$ ha, representando $11,48 \%$ e $28,25 \%$, respectivamente do custeio.

Os custos com fertilizantes e corretivos nas safras 2017/2018 e 2019/2020 foram respectivamente $R \$ 1005,90 /$ ha e $R \$ 1336,79 /$ ha, correspondendo a 33,86\% e $41,86 \%$ dos seus custeios. Já os custos com defensivos na safra $2017 / 2018$ foi de $\mathrm{R} \$ 799,75 /$ ha, representando $26,92 \%$ e a safra $2019 / 2020$ foi $R \$ 1132,34 /$ ha, correspondendo a $35,46 \%$. 
Pavão e Voese (2020), estudando dados do custeio da safra 2017/2018, obtidos pela Companhia Nacional de Abastecimento (CONAB), encontraram dados médios inferiores aos deste trabalho. $O$ valor médio gasto com sementes por hectare foi de $R \$ 264,44$, já os valores encontrados para fertilizantes e corretivos foi de $R \$$ $570,42 /$ ha e os valores gastos com defensivos foi $R \$ 546,47 /$ ha. Podendo se notar que a área de estudo teve um maior gasto com os principais insumos presentes no custeio, comparando tanto com a média regional como com a média nacional.

FIGURA 6. Comparação do Custeio da soja por safra, em porcentagem, da Fazenda Lagoa Dourada, em Poconé/MT.

\section{Custeio da Fazenda Lagoa Dourada}

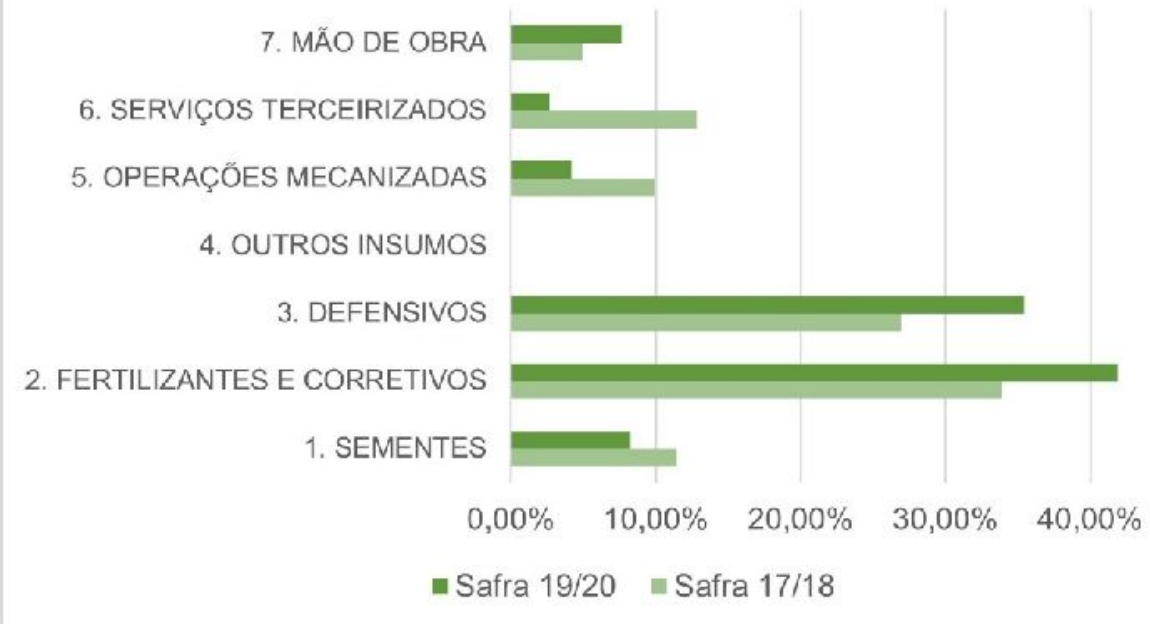

Na Figura 7 tem-se a comparação do COE da Fazenda Lagoa Dourada com o COE modal da região centro-sul do estado nas safras 2017/2018 e 2019/2020. Interessante destacar que 0 custeio, item A da Figura 7, representou aproximadamente $80 \%$ do valor do $\mathrm{COE}$, em todas as safras analisadas, tanto para a propriedade estudada quanto para o modal da região, validando a aplicação do Diagrama de Pareto (80/20) como ferramenta de gestão da qualidade na produção da soja.

Considera-se que o Diagrama de Pareto é uma das sete ferramentas da gestão qualidade e tem como princípio de que $80 \%$ das consequências vêm de $20 \%$ das causas. Neste estudo de caso, verificou-se que os demais itens que compõe 0 COE (B - manutenção, C- impostos e taxas, D- Financeiras, E- Pós-produção, F Outros custos e G - Arrendamento) possuem uma somatória que remetem a aproximadamente $20 \%$. Sendo assim, o produtor rural pode se basear nessa ferramenta da qualidade para gerenciar seus custos, pois caso seus resultados sejam desproporcionais a relação $80 / 20$, indica que os recursos não estão sendo utilizados de forma racional.

Segundo Koch (2015), o Princípio 80/20 afirma que ocorre um desequilíbrio entre as causas e os resultados, onde a maioria tem baixo impacto e a minoria tem alto impacto. Ou seja, os resultados são a derivação de uma pequena proporção das causas e esforços necessários para gerar esses resultados.

Resultados de COE com valores inferiores foram explanados por Rocha et al. (2019) numa propriedade no Estado de Goiás. Os autores encontraram um Custo Operacional Efetivo de $R \$ 3.129,98 /$ ha para a safra de 2017/2018. Neste estudo, 
para a mesma safra analisada, tem-se um COE de $R \$ 3.801,47 /$ ha. A Fazenda Lagoa Dourada apesar de apresentar um COE superior ao de Rocha et al. (2019), refletiu em dados de produtividade superiores aos da propriedade goiana. Importante salientar que isso também se repetiu na comparação da produtividade com os valores modais da região centro-sul mato-grossense e aos da média nacional brasileira.

FIGURA 7. Comparação do Custo Operacional Efetivo da soja por safra, em porcentagem, da Fazenda Lagoa Dourada, em Poconé/MT e da região Centro Sul do estado.

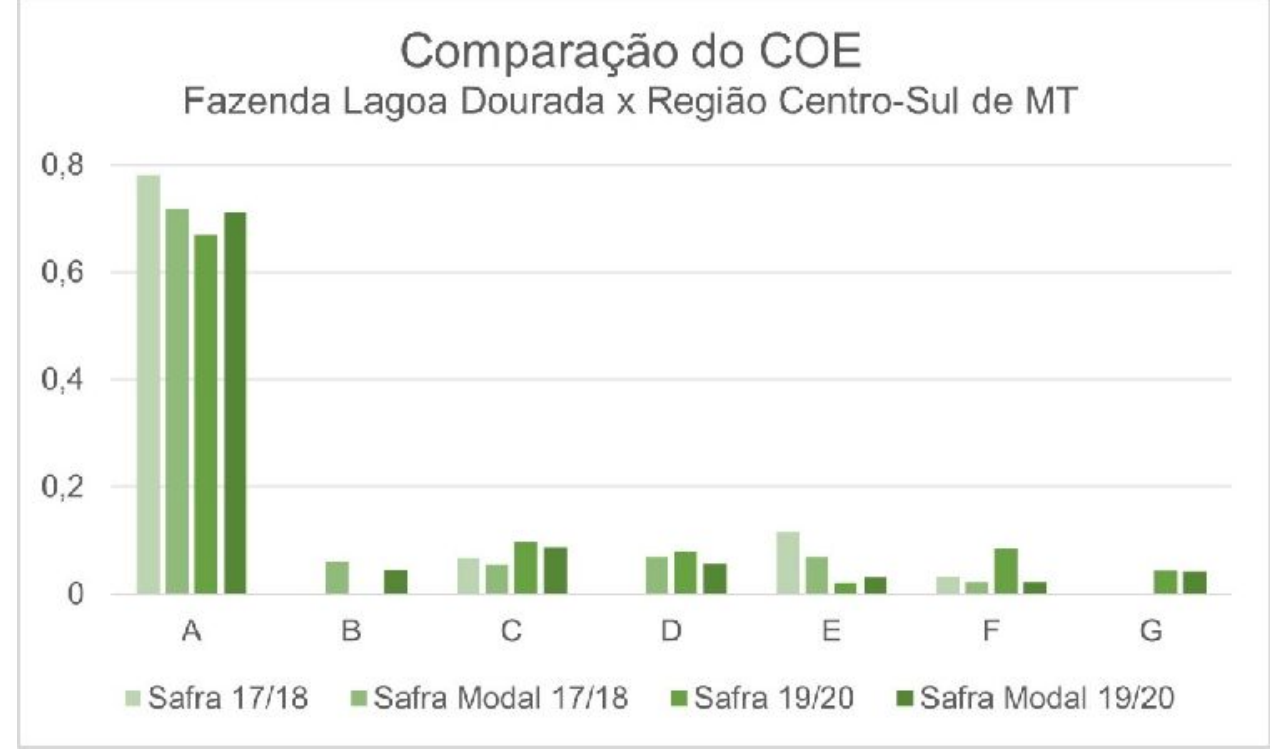

Vale ressaltar que a limitação metodológica do estudo de caso em questão, para a análise do COE, sem haver a integração com os custos operacionais totais (COT) e os custos totais (CT) do sistema produtivo não são suficientes para informar, com precisão, a gestão estratégica de custos, entretanto norteiam encaminhamentos, em especial no curto prazo. Outra limitação do estudo observado foi na dificuldade do lançamento quanto ao registro e detalhamento dos dados para cada rubrica específica no custeio, componente importante do COE.

\section{CONCLUSÕES}

Com finalidade de atendimento ao objetivo proposto e baseado nos resultados obtidos, conclui-se que:

As safras 2017/2018 e 2020/2021 foram as que apresentaram os melhores resultados;

A decisão por parte do produtor em aumento de $15,63 \%$ de área na safra 2020/2021 correspondeu a um aumento de produção de 31,43\%;

A propriedade estudada apresentou valores superiores de produtividade quando comparados as demais propriedades da região centro-sul de Mato Grosso, exceto na safra 2019/2020;

Com o passar do tempo a produtividade entre os talhões ficou mais homogênea, possivelmente pelo uso de técnicas da agricultura de precisão;

O COE da propriedade apresentou valores superiores aos dos modais das demais propriedades da região centro-sul de Mato Grosso; 
Aproximadamente $80 \%$ do COE correspondeu ao custeio em todas as safras analisadas validando a aplicação do Diagrama de Pareto como ferramenta de gestão da qualidade na produção .

Devido à limitação metodológica do estudo de caso em questão, para a análise do COE, sem haver a integração com os custos fixos e totais do sistema produtivo não são suficientes para informar, com precisão, a gestão estratégica de custos, entretanto norteiam encaminhamentos, em especial no curto prazo.

\section{REFERÊNCIAS}

AGRIHUB (Cuiabá). AgriHub. Disponível em: https://agrihub.com.br/. Acesso em: 19 dez. 2021.

AGRIHUB (Cuiabá). Rede de Fazendas Alfa. AgriHub. Disponível em: https://agrihub.com.br/rede-de-fazendas-alfa/. Acesso em: 19 dez. 2021.

CONAB. A produtividade da soja: análises e perspectivas. In: Compêndio de estudos. $\quad$ v.10, 35p. $2017 . \quad$ Disponível em:https://www.conab.gov.br/uploads/arquivos/17_08_02_14_27_28_10_compendio _de_estudos_conab_a_produtividade_da_soja_-_analise_e_perspectivas__volume_10_2017.pdf. Acesso em: 21 de dez. de 2021.

CONAB. Acompanhamento da safra brasileira de grãos: safra 2020/2021. Brasília: Conab, 2021. 98 p. Disponível em: file:///C:/Users/Usuario/Downloads/Ebook_BoletimZdeZSafrasZ-Z12oZlevantamento.pdf. Acesso em: 21 dez. 2021.

GIL, Antonio Carlos. Métodos e técnicas de pesquisa social. 6. ed. São Paulo: Atlas, 2009.

IMEA - Instituto Mato-Grossense de Economia Agropecuária (org.). Onde estão as grandes oportunidades do Agro? uma visão de dentro da porteira. Cuiabá, 2018. 44 p. Disponível em: https://www.imea.com.br/imea-site/view/uploads/estudoscustomizados/Onde_est\%C3\%A3o_as_\%20grandes_oportunidades_do_agro_Uma_ vis\%C3\%A3o_de_dentro_da_porteira.pdf. Acesso em: 19 dez. 2021.

IMEA - Instituto Mato-grossense de Economia Agropecuária. Custo de Produção. Cuiabá, 2020. Disponível em: https://www.imea.com.br/imeasite/view/uploads/metodologia/custos/CustosCustoProducao2020.pdf

$\mathrm{KOCH}, \mathrm{R}$. O Poder 80/20: os segredos para conseguir mais com menos nos negócios e na vida. São Paulo: Gutenberg, 2015.

LACERDA, J.J.J.; RESENDE, A.V.; FURTINI-NETO, A E.; HICKMANN, C.; CONCEIÇÃO, O. P. ;Adubação, produtividade e rentabilidade da rotação entre soja e milho em solo com fertilidade construída. Pesquisa agropecuária brasileira, Brasília, v.50, n.9, p.769-778, 2015.

PAIS, J.M.; TORRES, C.E.G. Logística de transportes e expansão da produção de soja no Centro Oeste. Revista de Economia do Centro-Oeste, Goiânia, v.4, n.2, p. 21-38, 2018. 
PAVÃO, J.A.; VOESE, S.B. Análise dos custos e da produtividade da soja convencional e transgênica no brasil nos anos de 2017 e 2018. Singular Sociais e Humanidades, Tocantins, n.1, v.1, p. 29-35, 2020.

RICHETTI, J. Modelos agrometeorológicos, espectrais e de inteligência artificial para estimação de produtividade de soja. 2018. 83f. Tese (Doutorado em Engenharia Agrícola). Universidade Estadual do Oeste do Paraná, Cascavel, 2018.

ROCHA, L. G.; RODRIGUES, C.C.; SANTANA, L.O.; SILVA, A.C.; ARAÚJO, M.S. Análise econômica de soja e milho safrinha em sucessão de culturas. Enciclopédia Biosfera, Goiânia, v.16 n.29; p. 130-140, 2019. 